\title{
Leagility in fashion supply chains: the potential of integration for managing complexity
}

\begin{abstract}
:
Offshore manufacturing and outsourcing trend in recent days in fashion industry complicates their supply chain (SC). This study focuses to this perplexity and assesses the potentiality of Leagility to achieve required competitiveness in such circumstances. The nature of the fashion supply chain is recapitulated and the aspect of Leagility is observed within existing literature and through case studies. The tendency of global sourcing, e.g. quick supply of manufacture economically obliges them to rethink the SC strategy and Leagility is beneficent in this context in absorbing the turbulence. This research provides a direction to the retailers unsure about the apt strategy by demonstrating the relevance of Leagility in fashion SC. It also builds the base for further deeper study for implement the concept in different part of manufacturing chain.
\end{abstract}

Keywords: leagility, supply chain, fashion industry, responsiveness, analytic hierarchy process

Available online at :

Leagility in fashion supply chains: the potential of integration for managing complexity by Shahriare Mahmood; Hanna Kropsu-Vehkaperä; Pekka Kess

International Journal of Management and Enterprise Development (IJMED), Vol. 18, No. 4, 2019, http://dx.doi.org/10.1504/IJMED.2019.10022923 


\section{INTRODUCTION}

Fashion industry is suppressed by multifaceted challenges because of the changed business environment in recent days and for the sector specific demands evolved from the effect of globalization. Although price combat is discernible, yet the market is demanding for quick replenishment, newness and customized products. Retailers source globally for their textiles and apparel products to acquire the cost benefits and in time to meet their fast moving and demanding consumer needs (Bruce et al., 2004). However, global sourcing does not always suffice to meet retailers' demands, particularly if they need to replenish a well selling stock mid-season, and so local suppliers are used in tandem with those offshore, as added by them. Supply chain (SC) complexity has increased as product variety grows, as the demand for customer-specific solutions increases and as more tasks and processes are outsourced and often moved offshore (Gaudenzi \& Christopher, 2015). Companies are enforcing better SC cooperation throughout which is often led by the retailers. In general, the retailer or brand owner, as the buying entity, is powerful and influences the structure, relationships and operational practices across the network (MacCarthy \& Jayarathne, 2013). According to them, a typical scenario is that a retailer based in a developed western economy works with a specific prime manufacturer based in a clothing production region in a less developed economy to supply a particular type of garment. This propagation complicates the SC organization, where a competitive strategy is essential.

Companies typically seek to respond to this competitive challenge by compressing time in critical supply chain processes (Gaudenzi \& Christopher, 2015). Agile supply chain is known for its quick response capability by means of some arrangement within the SC. For quite a long period of time, lean principle is adopted by many organizations to optimize their performance through eliminating wastes, which is according to Naim and Gosling (2011) elimination of all non-value adding activities, or muda. Likewise, other industries, fashion industry also seeking for favourable method which is yet to be adjudged. Christopher (2000) advocated that there will be occasions when a "pure" agile or a lean strategy might be appropriate for a supply chain, but there will often situations where a combination of the two may be appropriate. This paper intends to fill the gap in the research of SC coordination and the potential of this combination which is termed as Leagility.

The textiles and clothing industry is highly diverse and heterogeneous (Bruce et al., 2004). It is starving for expeditious operations from design till store. Getting the right product, at the right price, at the right time to the consumer is not only the lynchpin to competitive success but also the key to survival (MasonJones et al., 2000) until now. But it is almost unanimous that if a product is highly fashionable then, by its very nature, its demand will be unpredictable (Mason-Jones et al., 2000). The reality that is now gradually being accepted both by those who work in the industry and those who study it, is that the demand for fashion products cannot be forecast (Christopher et al., 2004). Therefore, companies are rather equipped to confront the unpredictability by minimizing the challenges rather than pre-determined method.

MacCarthy and Jayarathne (2013) stated that different types of clothing retailers serve different market segments. It is not unreasonable that some segment may apply lean principle to extract the cognizant advantages of lean, albeit it is commonly believed that agile philosophy is more suitable here. Nevertheless, different reasons can be advanced for prioritising agility or leanness (Gaudenzi \& Christopher, 2015). The typical problems that apparel manufacturers encounter are long distance from customers in the US and European markets, long production lead time, and forecasting errors for seasonal items (Chan \& Chan, 2010). The contemporary fast fashion supply chains brought a new dimension in the textile-apparel SC, where agile practice is well established despite of the mentioned challenges. Fast fashion retailers bring new products in few weeks from concept to store, which ultimately suppress the entire supply chain. The pressure excels in the upstream where manufacturers yearn for stable demand and high volume in order to achieve longed efficiency, often through lean practice. However, as the fashion supply chain (FSC) is dominated by the brands or retailers, the planning is naturally dependent and forecast from the buyers are uncertain.

A bunch of researches focused on the aptness of Lean, Agile and Leagile, but there is a lack of studies concentrating on the method of applicability of leagile concept in the FSC. In search of these facts and fill the research gap, this paper aims to investigate the potentiality of leagility through literature review and find out the critical SC priorities of the SC elements for this setup. This paper also discusses how such SCs can be organized within present knowledge on leagility. Research questions are formulated 
based on these objectives which are: 1 . Is leagile approach preferable compare to lean and agile solely? 2. What are the critical SC priority factors for this setup?

The rest of this paper is organized as follows: at first a literature review is made on lean, agile and leagile paradigms to learn the existing studies. The researches on leagility in the textile, apparel and fashion industry is also explored. Next, supply chain priority factors are examined by Analytic Hierarchy Process (AHP) from the data collected from the case study. Consequently, the results of the analysis by AHP is presented and the potential of leagility for such case is discussed. The paper concluded with the direction of further research scope.

\section{RESEARCH MODEL AND METHODOLOGY}

This exploratory type of research addresses the scope of leagility in FSC. The mixed approach appears in the researches which has the characteristics of both lean and agile systems and assumed to be beneficial in order to exploit market opportunities in a cost-efficient manner (Krishnamurthy \& Yauch, 2007). However, it demands for further scoping for the textile-apparel supply chain which strives for agility and historically strongly cost driven. Therefore, this specific research commits to analyse the fact through scientific approach. It has followed qualitative research technique based on the interactive model of research design by Maxwell (2012). The aim of the research is defined and the prior studies are planned accordingly. The methodology is described in this section and picture 1 depicts the process followed by the description of the steps.

Picture 1: Research model and methodology.

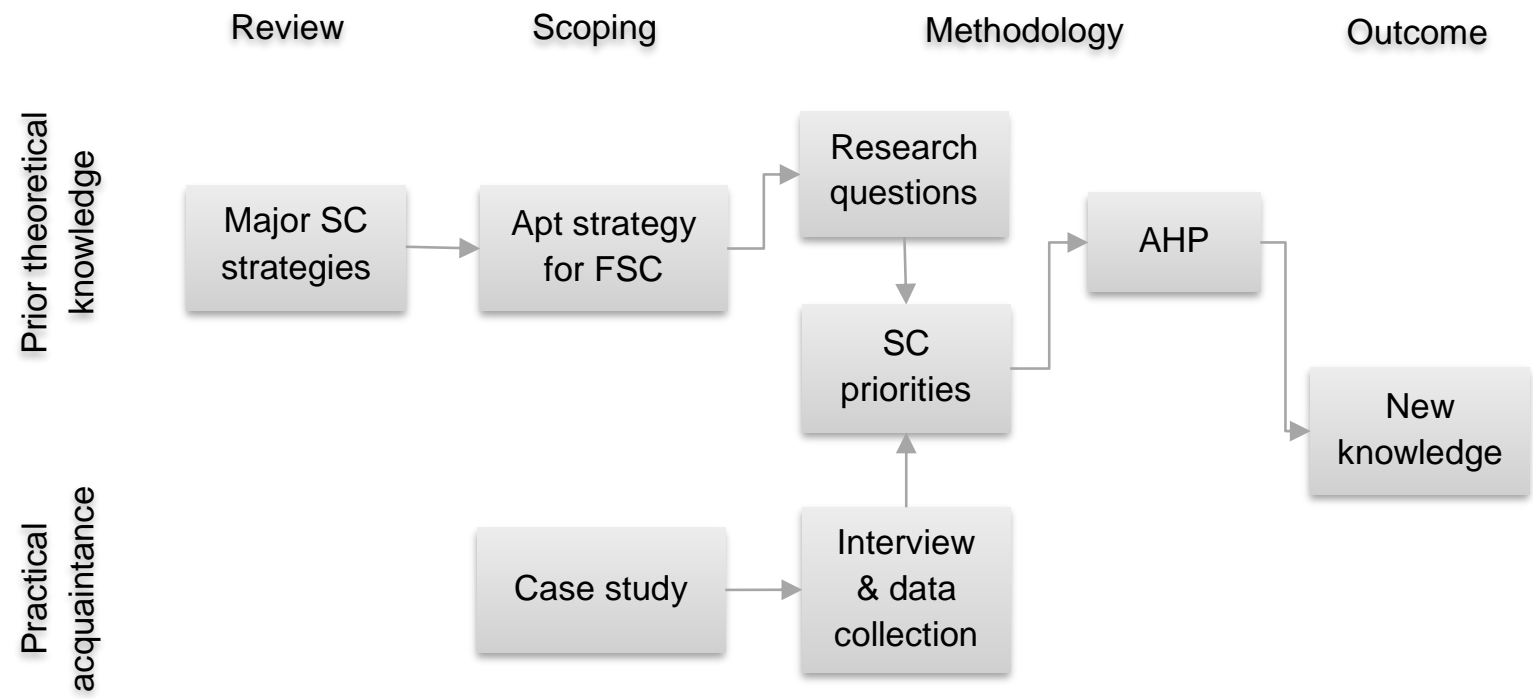

The demand-supply organization of fashion supply chain is studied to obtain a clearer picture. It is observed that the type of product mainly influences the supply chain strategy. To analyse the proper supply chain strategy for a specific setup, a Finnish case company is examined which deals with different product types and brands. The company deals with the final production, warehousing, distribution part of its own, although most of the other manufacturing activities in the upstream are outsourced. The warehouse and distribution remain close to the market, but they have nearshore manufacturing setup. Its SC is heavily dependent on the suppliers' performance in order to maintain the lead-time, cost etc. The prime areas of concerns are identified for their SC and data is collected through interviews to determine the key supply chain factor and essential dependency factors. The interviewees were selected who deal operationally with the suppliers and own production and corresponding operations. The contributors have expert knowledge on specific areas, although there were contributors who have more general view from strategic level. The purpose of this study was briefed well at the beginning and 
requested to share openly on this topic before the structured questions. As requested by the case company, the company name is withheld.

The purpose was to study whether the leagile SC strategy is beneficial for fashion companies in Finland and beyond. As their SCs are greatly sourcing dependent, it is almost inevitable that they should have a proficient and feasible SC strategy. Åkesson et al. (2007) stated in their assessment of sourcing strategies in the Swedish apparel industry that firms in the apparel industry have applied sourcing strategies utilizing low-cost supply markets for a long period of time. Although cost is a decisive factor, there are other factors which influence in choosing effective SC strategies. Therefore, this study considers multi-criteria decision-making (MCDM) model which is essential in decision-making processes (Tramarico et al., 2015). As they have stated, AHP is one of the most commonly used MCDM methods which is applied in a great variety of areas, including planning, selection of the best alternative, resource allocation and conflict resolution and the application of AHP in SC studies is increasing notably. In this study, AHP methodology is used in order to explore the correlation between the main affecting factors in the operations. The AHP is a multi-criteria decision-making tool developed by Saaty (1980) which is a systematic procedure for representing the elements of any problem, hierarchically (Sharma \& Bhagwat, 2007). AHP is a highly flexible decision-making methodology which allows decision makers to structure complex problems in the form of hierarchical manner or a set of integrated levels, having a certain number of levels from the root (objective) to the leaves (alternatives). (Chan \& Chan, 2010).

The procedure started with a literature review on lean, agile and leagile principles and corresponding practices in the supply chain and factors influencing them. Semi-structured interviews are organized in order to know ingenuously the true practices and challenges in the corresponding SC. However, the interviewees were given structured question also to obtain proper relative weights of the factors. Those factors are weighted by AHP's pair-wise comparisons which are then numbered through judgement (Table 1). AHP uses pair-wise comparison of the same hierarchy elements in each level (criteria or alternatives) using a scale indicating the importance of one element over another with respect to a higher-level element (Sharma \& Bhagwat, 2007). Matrices are formed from those pair-wise comparisons which are made in a series among the elements. Priorities obtained from the comparisons are used to weigh the priorities in the level immediately below (Saaty, 2008). Consequently, largest eigenvalue is calculated to compare with the number of elements. Consistency index $(\mathrm{Cl})$ is measured accordingly which allow to calculate the consistency ratio (CR). CR is calculated to check how consistent the pairwise comparison was.

Table 1: The fundamental scale of absolute numbers

\begin{tabular}{|l|l|l|}
\hline $\begin{array}{l}\text { Intensity of } \\
\text { Importance }\end{array}$ & Definition & Explanation \\
\hline 1 & Equal Importance & Two activities contribute equally to the objective \\
\hline 3 & $\begin{array}{l}\text { Moderate importance of } \\
\text { one over another }\end{array}$ & $\begin{array}{l}\text { Experience and judgment slightly favour one activity } \\
\text { over another }\end{array}$ \\
\hline 5 & $\begin{array}{l}\text { Essential or strong } \\
\text { importance }\end{array}$ & $\begin{array}{l}\text { Experience and judgment strongly favour one activity } \\
\text { over another }\end{array}$ \\
\hline 7 & Demonstrated importance & $\begin{array}{l}\text { An activity is strongly favoured and its dominance is } \\
\text { demonstrated in practice }\end{array}$ \\
\hline $2,4,6,8$ & $\begin{array}{l}\text { Extreme importance } \\
\text { Intermediate values } \\
\text { between the two adjacent } \\
\text { judgments }\end{array}$ & $\begin{array}{l}\text { The evidence favouring one activity over another is of } \\
\text { the highest possible order of affirmation }\end{array}$ \\
\hline $\begin{array}{l}\text { Reciprocals } \\
\text { of above }\end{array}$ & $\begin{array}{l}\text { If an activity has one of the } \\
\text { above numbers compared } \\
\text { with a second activity, then } \\
\text { the second activity has } \\
\text { the reciprocal value when } \\
\text { compared to the first }\end{array}$ & \\
\hline
\end{tabular}

Source: Saaty, 1980. 


\section{A REVIEW ON LEAN, AGILE AND LEAGILE}

There is a bunch of literatures on lean and agile, and more recently on Leagile paradigms after termed by Naylor et al., (1999). Lean and agile manufacturing are often described as two distinct manufacturing paradigms with different underlying goals (Krishnamurthy \& Yauch, 2007). Christopher and Towill (2001), and Christopher (2000) argue that agility should not be confused with leanness. The lean and agile paradigms, though distinctly different, can be and have been combined within successfully designed and operated total supply chains (Naylor et al., 1999; Mason-Jones et al., 2000). They have defined agile and lean manufacturing paradigms to emphasise the distinguishing features of leanness and agility.

Agility means using market knowledge and a virtual corporation to exploit profitable opportunities in a volatile market place.

Leanness means developing a value stream to eliminate all waste, including time, and to ensure a level schedule.

Lean and agile manufacturing systems share some commonalities with several other types of manufacturing improvement approaches, including flexible manufacturing, adaptable manufacturing, and mass customization (Krishnamurthy \& Yauch, 2007). They have mentioned that lean emphasizes reduction in wastage of resources, and lean implementation in a manufacturing system focuses on streamlining the flow for mixed-model production to capture the efficiencies of mass production while producing a greater variety of products. On the other hand, the agile manufacturing paradigm is best suited to satisfying a fluctuating demand (in terms of volume and variety) and lean manufacturing requires, and promotes, a level schedule (Naylor et al., 1999). It should be noted that what may be regarded as 'waste' in lean production may conversely be essential in agile production (Mason-Jones et al., 2000). According to them, in lean production, the customer buys specific products, whereas in agile production the customer reserves capacity that may additionally need to be made available at very short notice. They have also proposed that leanness and agility can sometimes be combined with the strategic use of a decoupling point, thereby capitalizing on the benefits of both paradigms as shown in picture 2. The similar thought is presented by Krishnamurthy \& Yauch (2007) where a supply chain hinges on the fact that the lean manufacturers are separated from the agile manufacturers in the chain by means of a separation point. This mixed approach is mentioned as Leagility in literatures. The commonly used definition of Leagility is also adopted from Naylor et al. (1999) which is as follows:

Leagility is the combination of the lean and agile paradigms within a total supply chain strategy by positioning the decoupling point so as to best suit the need for responding to a volatile demand downstream yet providing level scheduling upstream from the marketplace.

Bruce et al. (2004) mentioned that "Leagile" takes the view that a combination of lean and agile approaches be combined at a decoupling point for optimal supply chain management, which is same as mentioned on aforesaid definition. They have added that Leagile enables cost effectiveness of the upstream chain and high service levels in a volatile marketplace in the downstream chain. Gaudenzi \& Christopher (2015) also supported the same opinion which is cost-driven organisations need to create a lean supply chain, while service-based organisations seek agility. According to them, within decoupling point concept, the upstream lean supply chain is achieved through reducing variability and utilising standard processes and the downstream supply chain is agile-enabled by the late assembly of modules, configured to individual customer requirements.

Christopher and Towill (2001) proposed three practical ways of marrying the lean and agile paradigms in order to form leagile SC. The first hybrid strategy hinge on Pareto Rule, 80 percent of total volume will be generated from just 20 per cent of the total product line. They have suggested that the dominant $20 \%$ products by volume should be manufactured and distributed by following lean principle as they are likely to be more predictable. The rest $80 \%$ are less predictable, hence they should be produced in agile mode.

The second hybrid of lean and agile paradigms can be achieved through the creation of a decoupling point. It is based on strategic inventory where the inventory is hold as generic or modular form and upon receive of final product information from customer, final assembly will be done. By utilizing the concept of postponement, companies may utilize lean method up to decoupling point and agile methods beyond it. This approach works best when goods can be developed from common materials into a near-finished 
state with final touches to the product providing for a diverse assortment that accommodates distinct customer needs (Goldsby et al., 2006).

Christopher and Towill's (2001) third hybrid strategy is based on separation of "base" and "surge" demand. This distinction is proposed by possible level scheduling solution where capacity demands are smoothed by intelligent switching of "base" production. Past demand history is used for forecasting the base demand. In this case lean procedure can be used to achieve economies of scale. Whereas surge demand is difficult to calculate by the past demand information and therefore this category needs more flexibility in production. Agile method can be used to provide the required flexibility, even though it will be probably higher cost.

Picture 2: Block diagrams representing lean, agile, and Leagile supply (adapted from Mason-Jones et al. (2000))

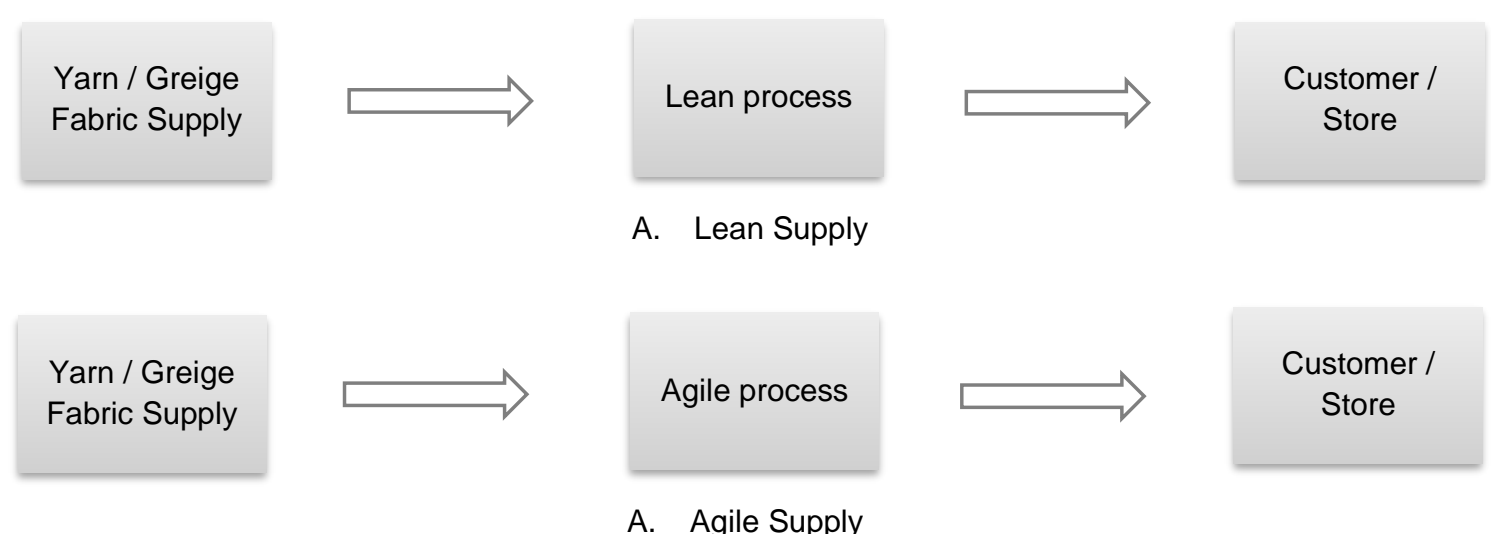

A. Agile Supply

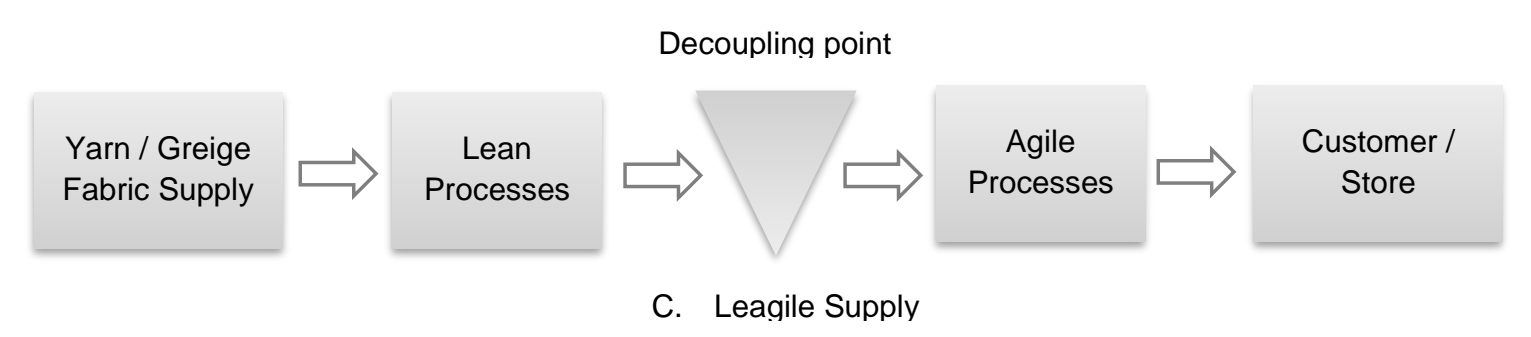

\subsection{Leagility in fashion industry}

It is already established within the literatures of lean and agile paradigm that the agile approach is more suitable for textile and clothing industry, in order to reduce lead times and achieve quick response (Bruce et al., 2004). Mason-Jones et al. (2000), stated that the characteristics of fashion products are more suited to the agile environment where the unpredictability of the demand is accepted as a business risk and the strategy is developed to optimize performance in such an arena. However, as cost efficiency is crucial for this industry, leanness also cannot be omitted. The sector has extremely low profit margins so that producing and even holding small quantities of stock is not commonly a viable option (Bruce et al., 2004). The costs and risks associated with holding speculative inventories are too great, especially with the products that have short life cycles or erratic demand and the risks of the obsolescence are high (Goldsby et al., 2006). In the volatile unpredictable marketplace for fashion' goods, both stockout and obsolescence costs are punitive (Mason-Jones et al., 2000; Christopher \& Towill, 2001). Bruce et al. (2004) conducted four case studies in fashion industry and found that fibre producer may be classified as lean, while a manufacturer of fashion goods, a sportswear accessory producer and a premium brand manufacturer / retailer may all be classified as leagile (Naim \& Gosling, 2011). 
The potential ways of combining leanness and agility vary significantly depending on the nature of the sectors' characteristics. Gaudenzi and Christopher (2015) have summarised the sector wise leagility drivers where driver for fashion sector is mentioned as virtual enterprise/cross-functional teamwork and decoupling point. The decoupling point separates the part of the supply chain geared towards directly satisfying customer orders from the part of the supply chain based on planning (Mason-Jones et al., 2000). The positioning of the decoupling point in fashion SC is strategic as the chain is relatively long and complex. The positioning of the decoupling point is also associated with the issue of postponement which increases the efficiency as well as the effectiveness of the supply chain (Mason-Jones et al., 2000). Postponing the decoupling point reduces the risk of being out of stock for long periods at the retailer and of holding too much stock of products that are not required (Naylor et al., 1999). They have illustrated that Benetton delayed the dyeing of their jumpers, which is the point at which the jumpers are differentiated, until the end of the process.

Beside decoupling point method, Christopher and Towill's (2001) third hybrid strategy is increasingly being employed in the fashion industry where the base demand can be sourced in low cost countries and the surge demand "topped up" locally nearer to the market. According to Christopher (2000), the pursuit of this hybrid strategy has enabled Zara to develop one of the most effective quick-response systems in its industry. Zara's strategy is to import the garments with the broadest and least transient appeal as finished goods from low-cost manufacturing centers in the Far East. The rest are produced by quick-response in Spain, using Zara's own highly automated factories and a network of smaller contractors. They keep the material or fabric in greige or raw form. It allows them to produce specfic product in particular color or print by the local or close by manufacturers quickly. Only those operations that enhance cost-efficiency through economies of scale (such as dying, cutting, labeling, and packaging) are conducted in-house and all other manufacturing activities, including the labor-intensive finishing stages, are completed by networks of more than 300 small subcontractors, each specializing in one particular part of the production process or garment type (Christopher, 2000).

\section{EVALUATION OF FACTORS BY AHP}

The main objective of this research is to explore the critical factors affecting the supply chain strategy in fashion industry. Accordingly, important factors are selected for the study which is based on literature review and case studies. The results of the SC factors are compared within existing literature to pursue the suitability of leagility.

In most of the cases, cost is the most important criteria between a buyer-supplier cooperation. Hence this study considers cost as a constant and basis for further study. While cost remains constant then other variables are compared amongst important SC factors. There are many SC factors appeared in the literatures some of which may have sector specific priority. It can be argued that quality, lead time, cost and service are essential competitive elements for all organisations (Gaudenzi \& Christopher, 2015). The priorities of SC elements vary among different segments which is an important phenomenon to consider for their success. Fashion supply chain success depends on factors like lead time, efficiency, service level, operational quality, flexibility, responsiveness etc. beside cost. For the pair-wise comparison, this study limits the apparel SC priorities to lead time, quality and responsiveness. These are presented in Picture 3 in the middle level of the three levels hierarchy. The lower level of the hierarchy contains materials, production and delivery as dependencies for plan SC and efficient execution.

By using AHP method SC priority factors calculation is made within the demonstrated hierarchy. To develop the weights for the SC priority factors, a pair-wise comparison matrix is filled in with the assigned numerical values from the judgement by using 1 to 9 scales in aforementioned table. Table 2 exhibits the pair-wise comparison matrix. Entries in the rows in matrix indicates the relative importance over the values in column. The $\mathrm{n}$-th root values of the rows are normalized to get weights of the factors as priorities. The sum of the weights of each criterion will be one when calculated correctly. Afterwards accuracy of the calculation is measured by consistency measure. This test evaluates the validity of the basic AHP pairwise comparison process (Chan \& Chan, 2010). In order to calculate the CR, at first $\mathrm{Cl}$ is calculated for the matrix which is 0.012 . Subsequently CR is measured to get a value 0.021 . Generally, 
the value of the consistency ratio should be around 10 percent or less to be acceptable (Sharma \& Bhagwat, 2007). The CR value for this matrix is reasonable according to the statement.

Picture 3: SC factors evaluation hierarchy.

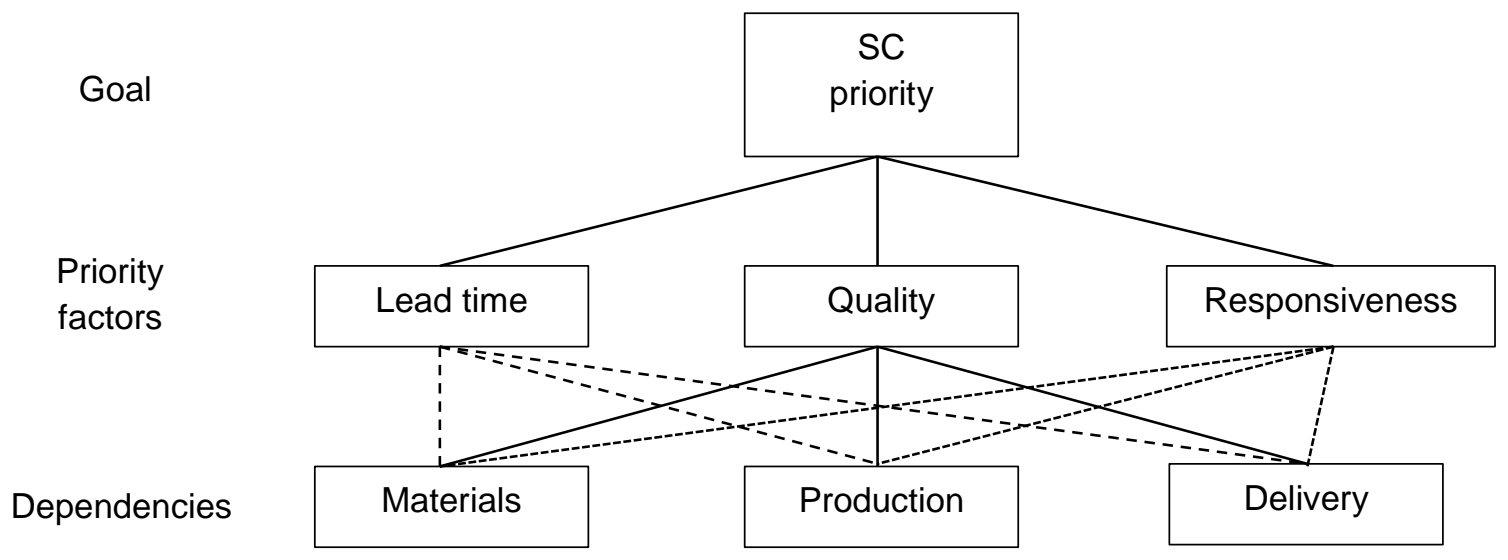

Table 2: Weights of the priorities of the key factors (middle level)

\begin{tabular}{|l|l|l|l|l|}
\hline & Lead time & Quality & Responsiveness & Weights \\
\hline Lead time & 1.00 & 2.00 & 5.00 & 0.570 \\
\hline Quality & 0.50 & 1.00 & 4.00 & 0.333 \\
\hline Responsiveness & 0.20 & 0.25 & 1.00 & 0.097 \\
\hline Sum & & & & 1.000 \\
\hline
\end{tabular}

Notes: Largest eigenvalue $=3.025, \mathrm{Cl}=0.012, \mathrm{CR}=0.021$

At the lower level, three dependency variables of priorities are considered for this study. A pair-wise comparison matrix for each of the variables are developed for each priority factors. Priority vectors for each of the matrix is obtained which are listed on Table 3. Maximum eigenvalue is calculated which are 3.029, 3.009, and 3.094 for lead time, quality and responsiveness respectively. The largest eigenvalue should be approximately equal to the number of elements in the comparison matrix (Sharma \& Bhagwat, 2007), which is 3 for the matrices in this study. Furthermore, CR also checked in each case which are $0.025,0.008$ and 0.081 respectively. Each CR value also met the aforementioned criteria.

Table 3: Dependencies with reference to priority factors.

\begin{tabular}{|l|l|l|l|l|}
\hline & Lead time & Quality & Responsiveness & Score \\
\hline Dependencies & 0.570 & 0.333 & 0.097 & 1.000 \\
\hline Materials & 0.659 & 0.458 & 0.537 & 0.580 \\
\hline Production & 0.156 & 0.416 & 0.364 & 0.263 \\
\hline Delivery & 0.185 & 0.126 & 0.099 & 0.157 \\
\hline Sum of dependencies & 1.000 & 1.000 & 1.000 & 1.000 \\
\hline
\end{tabular}

\section{DISCUSSIONS}

The evaluation revealed the main SC priority and figured out the corresponding dependencies within the boundary. It is found that lead time is comparatively more important than other factors for the given setup. Companies in fashion sector continuously striving to reduce the lead time which is also evident from the result. According to Christopher et al. (2004), there are three critical lead-times that must be managed by organisations that seek to compete successfully in fashion markets. These are time-to- 
market, time-to-serve and time-to-react. First one is the time to recognise a market opportunity and to translate this into a product or service and to bring it to the market. Serving corresponds to capture a customer's order and to deliver the product to the retail customer's satisfaction. Third one is related to react in order to adjust the output of the business in response to volatile demand. It is quite apparent that managing all of the three lead-time options require agile practice.

The case company also strive for finding out apt strategy to reduce the lead time and found that neither lean nor agile works solely applicable for them. The agile approach is required because of the nature of the business and structure of the supply chain. The customers of the case firm expect quick response for replenishment and often in small quantities. Therefore, agility is imposed naturally and the firm is obliged to ensue. However, as the company handles the final product manufacturing itself, agile is not the answer for efficient and cost-effective production. Especially as they have a nearshore production setup, the manufacturing cost is one of the most significant cost which can be reduced only through efficient and waste less process. It is obvious that they need both, agile for quick response and lean for efficient production and hence leagile found as most suitable approach. However, as the material supply also significant dependency, the positioning of the decoupling point is critical here.

Often material supply and apparel production is from different sources which means external dependencies. As the fibre and fabric manufacturing involves quite many stages and contains extensive processing, it is not as agile and flexible as apparel production. Generally, this part of the chain is expected to be leaner for the sake of the cost and process difficulties involved. This study also reveals that the material supply is more significant compared to other dependencies of SC factors. The discussion above and the result from the case study confirms that decoupling point is to be positioned between manufacturing and distribution. As both own production operation and material production require lean setup, it should be followed for reduction of waste both in context of cost and time. On the other hand, proper forecasting and planning is required to keep the right product in stock to enable response in no time.

The case company and corresponding study represents the similar scenario and challenges faced by many companies. Today's fashion market place is highly competitive and the constant need to "refresh" product ranges means that there is an inevitable move by many retailers to extend the number of "seasons", i.e. the frequency with which the entire merchandise within a store is changed (Christopher et al., 2004). In a quick response setting, products need to be delivered sometimes even in three to four weeks' time (Mahmood \& Kess, 2015). Corresponding literature review revealed that leagile is beneficial for fashion sector to absorb the turbulence. It is quite eminent that the lean philosophy singly is not very useful, but it is assumable that leanness is required in order to reduce cost by eliminating waste. In textile-apparel sector leagile is indeed feasible by positioning the decoupling point at the place up to which a level scheduling can be applicable. Fabric manufacturing part of this chain can be more standardized to eliminate the wastes due to wide varieties among others. Reduction of varieties will qualify for level scheduling. Product varieties can be produced through apparel design and post apparel ornamentation processing. Apparel production and post apparel processing are able to handle smaller batches with varieties more easily. Although leaner production is more effective, but according to market demand this part may need to adapt accordingly.

Brands can implement Leagile strategy for their fashion products which are generally affected by season, trends etc. In the current volatile market, consumer's demand in a fashion and textile product could change completely in a short time because an increasing star leads a new fashion trend, or a new product introduced by a competitor creates a high quality standard (Wang et al., 2012). A good example could be the products produced by garment dyeing method. In such cases, garment is produced from limited number of materials. By using the postponement method, garment can be made from the stocked materials which can be dyed in different colors even in small batches when the proper color information is obtained. Materials or fabrics of such kind of products and accessories used are often standard and can be produced by lean concept to achieve economies of scale. Apparel production and dyeing can be carried out by lean or agile concept depending on a specific setup.

\section{CONCLUSIONS}

SC coordination management is gaining serious study from both researchers and professional managers during the past few years (Wang et al., 2012). Particularly as textile-apparel sector is 
generally widely spread and multidimensional, it needs more attention in organizing the SC. Likewise other sectors, lean and agile method is attracted by the researchers and investigated for the appropriateness. Mason-Jones et al. (2000) argued that once leanness has been achieved, an enterprise should strive for agility. It is quite clear that both lean and agile approach has its own advantage, but none of them can be omitted in the SC. Furthermore, the common challenges in fashion industry, e.g. rapid response, varieties, newness, sustainability, ethical responsibility etc is likely to remain for long and they are directly linked to cost. In order to be really accountable for these by keeping the cost lower, an efficient and reasonable SC co-ordination is must. Bruce et al. (2004) mentioned that as low cost overseas manufacture is widely used to meet the reduced prices demanded by retailers, extended relationships with suppliers are key to SC management. They have argued that the textiles and clothing industry does not neatly fit into either a lean or agile paradigm, but instead it is a combination of the two driven by low margins and volatility of demand. However, the real challenge for organisations is to combine agility and leanness, as it is recognised that agility is not equally able to assure low-cost production (Gaudenzi \& Christopher, 2015).

Therefore, leagile brought the new dimension and literally solution for the industry to reduce the disequilibrium and utilize the benefits of both. However, it is critical that the SC lead should appreciate the phenomenon and look throughout the chain and distribute the load among different players. Proper placement of decoupling point is the most strategic decision which define the success of the entire chain. As this study represents a typical setup, it is believed to be helpful while reasoning own SC by a retailer. As an influential part of the SC brand owners and retailers should take the initiative which will be beneficent throughout the chain. But it is still to be researched what is the right method to follow by the retailers to organize a leagile SC which could benefit all the stakeholders. For the sake of deep understanding this research is narrowed to a specific segment of the fashion industry. However, it is necessary to explore the SC priority factors for other segments. It could be also useful to analyse the impact of different positioning of the decoupling point in a leagile SC. These knowledges will enable the practice leagility in SCs in fashion industries which is seen as a future approach for the industry.

Finally, this study attempted to add knowledge on SC organization and reduce complexity on fashion industry by adopting leagile paradigm. It has tried to explore what are the factors influencing the appropriate SC strategy for this industry. It is seen that although cost is the driver, but chasing for the lower price is not the only means for the issues. If cost is reduced by lean, flexibility costs more for being agile. The term leagility manifested under such circumstances. This paper identified the potential of leagility for textile-apparel sector that will become a future direction instead of bits and pieces of agile and lean. It is not necessary to follow agile approach throughout the chain which predominantly a success criterion for the retailers, but not the case always for the manufacturers. This research wants to establish the fact that downstream could operate with agile approach and upstream through lean by properly placing the decoupling point. Because the emphasis from the retailers on agile planning and execution in quick succession puts the chain in disequilibrium where upstream makers are fully dependent on the downstream plan. Appropriate planning and efficient production are the precondition for cost reduction in this industry.

\section{REFERENCES}

1. Bruce, M., Daly, L., \& Towers, N. (2004). Lean or agile: A solution for supply chain management in the textiles and clothing industry?. International Journal of Operations \& Production Management, Vol. 24 Iss: 2, pp.151 - 170.

2. Chan, F. T. S., \& Chan, H. K. (2010). An AHP model for selection of suppliers in the fast changing fashion market. Int J Adv Manuf Technol, Vol. 51, pp.1195 - 1207.

3. Christopher, M. (2000). The Agile Supply Chain: Competing in Volatile Markets. Industrial Marketing Management, Vol. 29, pp. 37 - 44.

4. Christopher, M., Lowson, R., \& Peck, H. (2004). Creating agile supply chains in the fashion industry. International Journal of Retail \& Distribution Management, Vol. 32 Iss 8 pp. 367 376. 
5. Christopher, M., \& Towill, D. (2001). An integrated model for the design of agile supply chains. International Journal of Physical Distribution \& Logistics Management, Vol. 31 Iss 4 pp. 235 246.

6. Gaudenzi, B., \& Christopher, M. (2015). Achieving supply chain 'Leagility' through a project management orientation. International Journal of Logistics: Research and Applications, Vol. 19 No. 1 , pp.3 - 18.

7. Goldsby, T. J., Griffis, S. E., \& Roath, A. S. (2006). Modeling Lean, Agile, and Leagile supply chain strategies. Journal of Business Logistics, Vol. 27 No. 1, pp.57 - 80.

8. Krishnamurthy, R., \& Yauch, C. A. (2007). Leagile manufacturing: a proposed corporate infrastructure. International Journal of Operations \& Production Management, Vol. 27 No. 6 , pp. $588-604$.

9. MacCarthy, B. L., \& Jayarathne, P. G. S. A. (2013). Supply network structures in the international clothing industry: differences across retailer types. International Journal of Operations \& Production Management, Vol. 33 Iss: 7, pp. 858 - 886.

10. Mahmood, S., \& Kess, P. (2015). An assessment of the organization of demand supply chains in the fashion industry. Proceedings of the MakeLearn and TIIM Joint International Conference, Retrived from http://www.toknowpress.net/ISBN/978-961-6914-130/papers/ML15-099.pdf

11. Mason-Jones, R., Naylor, B., \& Towill, D. R. (2000). Engineering the leagile supply chain. International Journal of Agile Management Systems, Vol. 2 Iss 1 pp. 54 - 61.

12. Mason-Jones, R., Naylor, B., \& Towill, D. R. (2000). Lean, agile or leagile? Matching your supply chain to the marketplace. International Journal of Production Research, Vol. 28, Iss 17 , pp. $4061-4070$.

13. Maxwell, J.A. (2012), Qualitative Research Design: An Interactive Approach. SAGE Publications.

14. Naim, M. M., \& Gosling, J. (2011), On leanness, agility and leagile supply chains. Int. J. Production Economics, Vol. 131, pp. 342-354.

15. Naylor, J. B., Naim, M. M., \& Berry, D. (1999), Leagility: Integrating the lean and agile manufacturing paradigms in the total supply chain. Int. J. Production Economics 62, pp. 107 118.

16. Saaty, T. L. (1980). The Analytical Hierarchy Process. McGraw-Hill, New York, NY.

17. Saaty, T. L. (2008). Decision making with the analytic hierarchy process. Int. J. Services Sciences, Vol. 1, No. 1, pp. 83-98.

18. Sharma, M. K., \& Bhagwat, R. (2007). An integrated BSC-AHP approach for supply chain management evaluation. Measuring Business Excellence, Vol. 11 Iss: 3, pp.57 - 68.

19. Tramarico, C. L., Mizuno, D., Salomon, V. A. P., \& Marins, F. A. S. (2015). Analytic Hierarchy Process and Supply Chain Management: a bibliometric study. Information Technology and Quantitative Management, Vol. 55, pp. $441-450$.

20. Wang, K., Gou, Q., Sun, J., \& Yue, X. (2012). Co-ordination of a fashion and textile supply chain with demand variations. J Syst Sci Syst Eng, Vol. 21, pp. $461-479$.

21. Åkesson, J., Jonsson, P., \& Edanius-Hällås, R. (2007). An assessment of sourcing strategies in the Swedish apparel industry. International Journal of Physical Distribution \& Logistics Management, Vol. 37 Iss: 9, pp.740 - 762. 